\title{
Pitfalls in interpreting thyroid function tests: antibodies causing assay interferences
}

\author{
S Pathmanathan ${ }^{1}$, N P Somasundaram ${ }^{1}$, S Siriwardena ${ }^{2}$ \\ Sri Lanka Journal of Diabetes, Endocrinology and Metabolism 2015; 5: 20-22
}

\begin{abstract}
Many factors can compromise results of thyroid function tests, leading to possible misinterpretation and misdiagnosis. Presence of antibodies in the human serum can react with the immunoglobulins included in the assay components and cause anomalous results. We describe below three cases where spurious hormone results were obtained due to interfering antibodies.
\end{abstract}

\section{Introduction}

Thyroid dysfunction has diverse clinical presentations, where the majority of thyroid disease symptoms are often subtle and nonspecific. Therefore requests for investigation of assessing thyroid function are often made even in the absence of supporting clinical evidence. Unlike in the West, where thyroid function tests (TFT) are performed as routine tests in an asymptomatic patient, these tests are not widely performed in our setup unless there are certain indications. When the clinical suspicion is strong, TFT are helpful in confirming the diagnosis. However in situations where the managing physicians receive 'abnormal' test results discordant with the clinical findings, these results may be misinterpreted resulting in an erroneous diagnosis leading to inappropriate management being instituted. Thus clinicians should be vigilant while interpreting abnormal and unusual TFT. We present three brief case histories to emphasize the importance of clinicians having a vigilant mind in interpreting these unusual TFT (1-4).

\section{Case 1 - a lady with primary hypothyroidism (heterophile antibodies causing assay interferences)}

A 52-year-old woman was referred from Ear Nose Throat (ENT) unit for abnormal thyroid functions. She had symptoms and signs suggestive of hypothyroidism. She had a low $\mathrm{FT}_{4}$ along with a low TSH which was reconfirmed by repeated testing; $3^{\text {rd }}$ generation TSH was 0.08 (normal $0.5-4.0 \mathrm{mIU} / \mathrm{L}$ ), and the $\mathrm{FT}_{4} 0.3 \mathrm{ng} / \mathrm{dL}$ (normal $0.8-1.8 \mathrm{ng} / \mathrm{dL})$. As she had had early menopause at 40 years, secondary hypothyroidism was suspected and she underwent detailed anterior pituitary function tests which were all within normal limits. (FSH and LH were in the menopausal range, $9 \mathrm{AM}$ cortisol was $325 \mathrm{nmol} / \mathrm{L}$ and cortisol value 30 minutes after $250 \mathrm{mcg}$ of syancthen (synthetic ACTH) was normal with a 30-minute value of $1011 \mathrm{nmol} / \mathrm{L})$. When such a clinically discrepant result was observed in this patient, we suspected the possibility of heterophile antibodies causing assay interferences and decided to retest with a different immunoassay method (she was initially tested by chemiluminescence method). Re-analysis by manual immunoradiometric assay (IRMA) gave an elevated TSH of $>50 \mu \mathrm{IU} / \mathrm{mL}$ and further polyethylene glycol (PEG) precipitation by $1: 1$ dilution studies were carried out which yielded a TSH result of $91.8 \mu \mathrm{IU} / \mathrm{mL}$.

She was diagnosed as having primary hypothyroidism with heterophile antibodies causing TSH assay interference. She was started on L-thyroxine replacement, which promptly resolved her symptoms. It was decided to follow her with free $\mathrm{T}_{4}$ to look for adequacy of thyroxine replacement and if TSH has to be repeated, to do her blood tests using assays that shows no interference to avoid confusion.

\section{Case 2 - euthyroid hyperthyroxinaemia due to assay interference}

A 33-year-old lady on antipsychotic medications (Olanzapine 5mg nocte and Benzhexol $2 \mathrm{mg}$ mane) was noticed to have a weight loss of $2 \mathrm{~kg}$ which prompted the managing clinician to request for a TFT. She was shown to have elevated $\mathrm{FT}_{4}$ and normal TSH which was reconfirmed on two occasions $\left(\mathrm{FT}_{4}-2.09 \mathrm{ng} / \mathrm{dL}(0.89-1.76)\right.$, $3^{\text {rd }}$ generation TSH - $\left.1.07 \mu \mathrm{IU} / \mathrm{mL}\right)$. These tests were done by chemiluminescence method. She was otherwise well and did not have any other symptoms of hyperthyroidism or family history of thyroid disorders. At the time of

${ }^{1}$ Department of diabetes and endocrinology, National hospital of Sri Lanka, ${ }^{2}$ Department of chemical pathology, National hospital of Sri Lanka. 
presentation her psychiatric condition was stable and clinically the patient was euthyroid with no goiter and normal in all respects.

A possibility of assay interference was considered to be the most likely explanation for the elevated free thyroxine level. Thyroid hormone resistance and TSHproducing tumour seemed less likely in our patient. Blood samples were retested by IRMA which reconfirmed persistently high $\mathrm{FT}_{4}$ with normal TSH. Therefore we decided to measure total $\mathrm{T}_{4}$, which was well within the normal adult range $(5.17 \mu \mathrm{g} / \mathrm{dL}$ (normal 4.5-12)). An antibody interfering with the free hormone assay was thought to be the most likely cause as she did not have any other conditions that could explain a raised free thyroxine level. The patient was reassured and it was recommended to her that in the future she should have her thyroid function tests done using the total hormones to avoid confusion and unnecessary investigations and treatment.

\section{Case 3 - elevated free $T_{3}$ due to assay interference}

A 33-year-old overweight lady was referred from a medical unit for abnormal thyroid function tests. She has been screened for secondary causes for her overweight state. During examination she was noticed to have a thyroid lump which prompted the managing clinician to request for TFT, which revealed elevated $\mathrm{FT}_{3}$, normal $\mathrm{FT}_{4}$ and TSH $\left(\mathrm{FT}_{3}-4.23 \mathrm{pg} / \mathrm{ml}(1.5-4.1), \mathrm{FT}_{4}-1.1 \mathrm{ng} / \mathrm{dL}\right.$ (0.89 1.76), $3^{\text {rd }}$ gen TSH - $1.74 \mu \mathrm{IU} / \mathrm{ml}$ ). (These tests were done by chemiluminescence enzyme immunoassay method). She denied any other symptoms of hyperthyroidism or family history of thyroid disorders. At the time of presentation clinically the patient was euthyroid with no goiter (which was confirmed on USS) and normal in all respects.

In view of the clinical findings, a possibility of assay interference was considered to be the most likely explanation for the lack of clinical correlation with the blood results. Therefore we decided to measure total $\mathrm{T}_{3}$ which was well within the normal adult range $(1.18 \mathrm{ng} / \mathrm{ml}(0.58$ 1.59). (These tests were done by chemiluminescence micro particle immunoassay method) The patient was reassured but continued follow-up for management of her overweight state.

\section{Discussion}

The presence of circulating, endogenous antibodies directed against a number of antigens may cause either falsely depressed or falsely increased values in TFT. The outcome mainly depends on the nature of the interfering antibody or the assay design. The major importance of appreciating antibody interference as a confounding factor in the interpretation of TFT is that it can prevent inappropriate investigations and treatment, and unnecessary stress to the patient $(3,5)$.

The three major possible sources of antibody interference in thyroid hormone immunoassays are autoantibodies, heterophile antibodies, and rheumatoid factors (RF). Autoantibodies cause analyte-specific interference while heterophile antibodies and rheumatoid factors are responsible for method-specific disturbances. Autoantibodies include antibodies to thyroglobulin, microsomal thyroid peroxidase and TSH receptor, as well as antibodies reacting with $\mathrm{T}_{4}$ and $\mathrm{T}_{3}$. Many different approaches may be utilized to overcome the interference, e.g. PEG precipitation $(3,5)$.

Heterophile antibodies are antibodies against specific animal immunoglobulins which could cross react with the antibodies used in the assay. The effect of heterophile antibodies on laboratory results depend on the nature and concentration of the interfering antibody and on the immunoassay method used. These antibodies when present can promote binding between the capture antibody and the signal antibody, even in the absence of the analyte. This type of nonspecific binding results in abnormally high values. However heterophile antibody can also bind only to the capture antibody and can affect the conformation of the variable region, even without binding directly to the recognition site of the analyte, thereby causing abnormally low values $(3,5,6,7)$.

When interpreting TFT, it is important to consider antibody interference in a patient with discrepant results. Routine communication between the chemical pathologist and the clinician is essential to arrive at the correct diagnosis. The laboratory should then be requested to repeat the suspect sample to confirm whether the presence of the interfering antibodies were responsible for the spurious result. Samples are typically re-evaluated using an alternative method and the removal of the interfering antibody (e.g. by PEG), or by using antibody-blocking reagents. Results on reanalysis that are different after the removal of interfering antibodies are indicative of antibody interference and usually will correlate well with the clinical picture (8-11).

\section{Conclusion}

TFT should not be interpreted in isolation. A good rule of thumb is that the tests should be concordant with the clinical picture and between themselves - demonstrating feedback loops. If the clinical picture and biochemistry are discordant, various possibilities including assay interferences should be considered. If the TSH and thyroxine hormone tests are discordant i.e. feedback loop appear to have been broken, then common as well as rare 
illnesses (patient non compliance, TSHoma, Thyroid Hormone Resistance Syndrome) as well as antibody interference should be considered. Communication between the requesting clinician and the chemical pathologist is therefore key for correct interpretation and management of these patients.

\section{References}

1. Haarburger D. Thyroid disease: thyroid function tests and interpretation. Continuing Medical Education 2012; 30(7): 241.

2. Fedler C. Laboratory tests of thyroid function: Pitfalls in interpretation CME 2006; 24(7): 386-90.

3. Muthukuda DT, Bulugahapitiya U. Interpretation of thyroid function tests: a challenge to the clinician? Sri Lanka Journal of Diabetes, Endocrinology and Metabolism 2013; 3: 1-3.

4. Sisson JC. Principles of, and Pitfalls in, Thyroid Function Tests. Journal of Nuclear Medicine 1965; 6: 853-901.

5. Fowler MJ, Pannone AF, Blevins LS. Pitfalls to Avoid
While Interpreting Thyroid Function Tests: Five Illustrative Cases. Southern Medical Journal 2002; 95(5): 486-92.

6. Despres N, Grant AM. Antibody interference in thyroid assays: a potential for clinical misinformation. Clinical Chemistry 1998; 44:440-54.

7. Fiad TM, Duffy J, McKenna TJ. Multiple spuriously abnormal thyroid function indices due to heterophilic antibodies. Clinical Endocrinology 1994 ; 41( 3): 391-5.

8. Kricka LJ. Human anti-animal antibody interferences in immunological assays. Clinical Chemistry 1999; 45(7): 942-56.

9. Paul N, Nicolai GN, Geurts-Moespot CGJ. Sweep Screening for Interference in Immunoassays. Clinical Chemistry 2003; 49(10): 1708-9.

10. Miller JJ, Valdes R. Approaches to Minimizing Interference by Cross-Reacting Molecules in Immunoassays. Clinical Chemistry 1991; 37(2): 144-53.

11. Baird CL, Tan R, Christopher J, et al. Reducing heterophilic antibody interference in immunoassays using single-chain antibodies. Analytical Biochemistry 2011; 419(2): 333-5. 